Article

\title{
Parametric Assessment of Seasonal Drought Risk to Crop Production in Bangladesh
}

\author{
Mahiuddin Alamgir ${ }^{1}\left(\mathbb{D}\right.$, Morteza Mohsenipour ${ }^{1}{ }^{(}$, Rajab Homsi $^{1}$, Xiaojun Wang ${ }^{2,3, *}$, \\ Shamsuddin Shahid ${ }^{1} \oplus$, Mohammed Sanusi Shiru ${ }^{1}$, Nor Eliza Alias ${ }^{1,4}$ and Ali Yuzir ${ }^{5}$ \\ 1 Department of Water and Environmental Engineering, School of Civil Engineering, \\ Universiti Teknologi Malaysia (UTM), 81310 Johor Bahru, Malaysia; malamgirutm@gmail.com (M.A.); \\ mortezamohsenipour@gmail.com (M.M.); eng.rajabhomsi@gmail.com (R.H.); sshahid@utm.my (S.S.); \\ shiru.sanusi@gmail.com (M.S.S.); noreliza@utm.my (N.E.A.) \\ 2 State Key Laboratory of Hydrology-Water Resources and Hydraulic Engineering, \\ Nanjing Hydraulic Research Institute, Nanjing 210029, China \\ 3 Research Center for Climate Change, Ministry of Water Resources, Nanjing 210029, China \\ 4 Centre for Environmental Sustainability and Water Security (IPASA), Universiti Tecknologi Malaysia (UTM), \\ Johor Bahru 81310, Malaysia \\ 5 Disaster Preparedness and Prevention Center, Malaysian-Japan International Institute of Technology (MJIIT), \\ UTM Kuala Lumpur, Jalan Sultan Yahya Petra (Jalan Semarak), Kuala Lumpur 54100, Malaysia; \\ muhdaliyuzir@utm.my \\ * Correspondence: xjwang@nhri.cn; Tel.: +86-025-8582-8539
}

Received: 22 December 2018; Accepted: 25 February 2019; Published: 8 March 2019

check for updates

\begin{abstract}
Droughts are more damaging when they occur during crop growing season. This research assessed the spatial distribution of drought risks to crops in Bangladesh. Catastrophe theory-based weighting method was used to estimate drought hazard, exposure, and risk by avoiding potential human bias. Ten major crops, including eight different types of rice, wheat, and potato, were selected for evaluation of drought risk. Results showed that 32.4\%, 27.2\%, and 16.2\% of land in Bangladesh is prone to extreme Kharif (May-October), Rabi (November-April), and pre-Kharif (March-May) droughts, respectively. Among the major crops, Hybrid Boro rice cultivated in $18.2 \%$ of the area is found to be highly vulnerable to droughts, which is followed by High Yield Varity (HYV) Boro (16.9\%), Transplant Aman (16.4\%), HYV Aman (14.1\%), and Basic Aman (12.4\%) rice. Hybrid Boro rice in 12 districts, different varieties of Aman rice in 10 districts, and HYV Boro rice in 9 districts, mostly located in the north and northwest of Bangladesh, are exposed to high risk of droughts. High frequency of droughts and use of more land for agriculture have made the region highly prone to droughts. The methodology adopted in this study can be utilized for unbiased estimation of drought risk in agriculture in order to adopt necessary risk reduction measures.
\end{abstract}

Keywords: seasonal droughts; catastrophe theory; crop vulnerability; drought risk; Bangladesh

\section{Introduction}

Droughts, floods, pests, labor shortage, price fluctuations, and political factors influence risks to agricultural production in most countries in the world [1-4]. However, the effects of climate on agriculture are more significant compared to other factors. Drought is a global phenomenon, which occurs as a consequence of variability in climate [5-8]. Among the natural disasters, droughts have much more devastating effects, and thus are the costliest natural disaster $[9,10]$. There are different types of droughts, but meteorological droughts are most widely studied as they are the trigger for the other kinds of droughts [11,12]. 
Bangladesh is amongst the top disaster-prone countries in the world [13]. Droughts constitute a major natural disaster that often affects the agronomics of the country [14]. The critical drought in 1978-79 [15] affected $44 \%$ of the populace and $42 \%$ of areas cultivated in Bangladesh [16,17]. According to [18], the vulnerability of the land in Bangladesh to droughts is up to 2.7 million hectares annually. Estimates by the Climate Change Cell of Bangladesh showed that $83 \%$ of the Kharif and Rabi crop lands are exposed to different severities of droughts.

Drought management measures have been taken by the Bangladesh government to reduce drought effects. However, the governmental initiatives for drought management have focused largely on response and drought recovery, with not much attention paid to monitoring, preparation, and mitigation of droughts. Attention has been drawn in recent years from a crisis approach to a risk approach in the management of droughts across the globe. Reliable drought risk assessment is an important aspect of managing droughts [7], as it cements the relationship between the hazard and the society.

Studies have been conducted to assess drought impacts on agriculture [2,4], crop production [17], land degradation [19], the economy [20], and the society [21] of Bangladesh. Drought characterization during cropping seasons has been assessed [2,6,14,22]. However, these studies didn't give any indication of seasonal drought risks, especially for cropping periods. The economic impact of droughts are more pronounced when they overlap with the crop growing period $[5,6,23]$. This emphasizes the need to estimate seasonal drought hazards and their risk to crops.

Drought risk maps are generally prepared through integration of drought hazard, vulnerability, and exposure maps. Generally, weighted integration methods are used for preparation of risk maps [14,24], where weights are estimated using either data-driven or knowledge-driven methods. In data driven methods, the weights are estimated from observed data, while in knowledge driven approach, it is estimated from previous knowledge $[25,26]$. In data-driven methods, the influence of one factor over the others is estimated only from observed data, and therefore, subjectivity in weighting can be avoided [25,27]. Catastrophe theory is one such method which can be particularly applied where sudden effects arise as a result of gradually changing forces [25,28,29]. Therefore, it can be an effective approach to assess drought risk. Catastrophe theory has been applied successfully in the field of water resources, such as water security assessment [30], water quality assessment [31,32], evaluation of groundwater potential [5,26], and flood risk assessment [33].

The assessment of the spatial distribution of seasonal drought risks to crops in Bangladesh using a catastrophe theory-based weighting method is the major objective of this study. The main criteria used in the study for evaluating drought risk are: (1) hazard with regard to its severity and return period; (2) exposure in respect of crop area and crop yield; and (3) risk as a function of hazard and exposure. It is expected that the maps generated in this study can be used for adaptation planning for reduction of droughts risks, and for sustainable development of agriculture in Bangladesh. Furthermore, the proposed methodology can be applied for unbiased estimation of drought risk in agriculture or any other sector for better management of disaster risk.

\section{Materials and Methods}

\subsection{Description of the Study Area}

The climate in Bangladesh is of the tropical monsoon type, characterized by rainfalls varying widely seasonally, and high temperature and humidity [34,35]. Annually, the average rainfall within the country varies between 1500 and $4300 \mathrm{~mm}$ from the northwest to the northeast [36]. In addition, annual and seasonal variability of rainfall is very high, which has made the country prone to droughts [13,22,37]. The effect of droughts on agriculture is significant in Bangladesh [38]. There is direct or indirect involvement of a significant population of Bangladesh in different agricultural activities [39]. Crop production is vital in the agricultural sector relating to food security, income generation, poverty reduction, and political stability in Bangladesh. Therefore, reduction of crop 
production due to natural hazards significantly affects the economy and livelihoods of the people of the country.

\subsection{Data and Sources}

Fifty-year (1961-2010) monthly rainfall data recorded at 29 stations across Bangladesh were used in this study (Figure 1). However, there are missing data for some stations during 1971; hence, the data for the year at all stations were discarded. The percentage of missing data was found to be less than $2 \%$ after removal of records for the year 1971 .

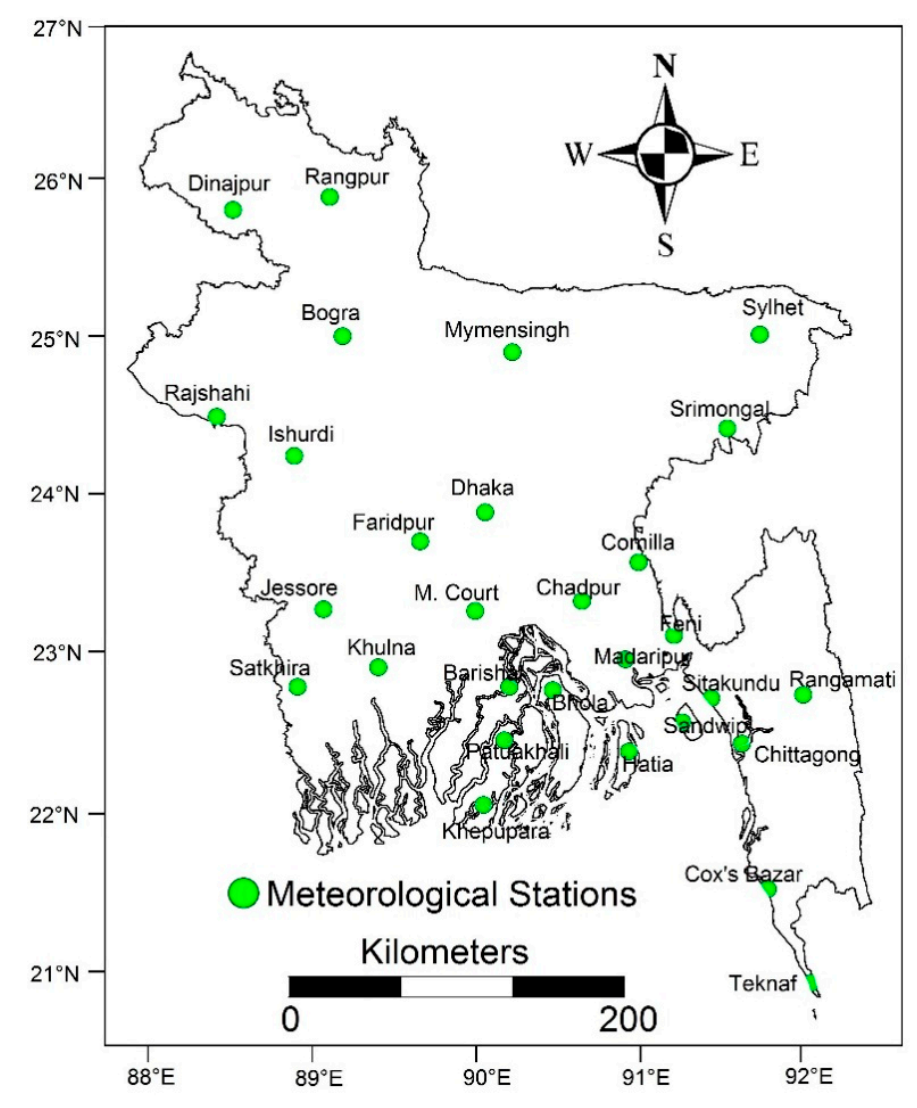

Figure 1. Location of rain gauges in Bangladesh.

Administrative district level data of cultivated land area and yield per hectare of land averaged for the period 2001-2011 were collected from the Yearbook of Agricultural Statistics of Bangladesh [40]. Data for ten major crops were collected, namely, Local Aus (L Aus), High Yield Variety Aus (HYV Aus), Basic Aman (B Aman), High Yield Variety Aman (HYV Aman), Transplant Aman (T Aman), Local Boro (L Boro), High Yield Variety Boro (HYV Boro), Hybrid Boro (H Boro), Wheat, and Potato. Cultivation periods of the crops are shown in Table 1. Wheat and potato are grown during November-April, which is known as Kharif season. The rice varieties L Aus, HYV Aus, B. Aman, HYV Aman, and T Aman are grown during May-October, which is known as Rabi season. The rice varieties L Boro and HYV Boro are grown during January-May, which are affected by droughts during March-May, known as pre-Kharif season. Therefore, it is imperative to assess drought risk to crops during Kharif, Rabi, and pre-Kharif seasons. 
Table 1. The crop calendar of Bangladesh. The shaded gray areas in the table indicate the cultivation periods.

\begin{tabular}{|c|c|c|c|c|c|c|c|c|c|c|}
\hline Crop & Jan & Feb & Mar Apr & May & Jun Jul & Aug & Sep & Oct & Nov & Dec \\
\hline $\begin{array}{l}\text { L Aus/HYV Aus/B Aman/I } \\
\text { Aman/T Aman/HYV Boro }\end{array}$ & & & & & & & & & & \\
\hline L Boro/HYV Boro & & & & & & & & & & \\
\hline Wheat/Potato & & & & & & & & & & \\
\hline
\end{tabular}

\subsection{Methodology}

The drought risk to crops was conceptualized from the definition of risk defined by Intergovernmental Panel for Climate Change [41]. Drought is a natural hazard which may have adverse effects on crops. The possibility of crop losses due to droughts is the drought risk to crops. The drought risk to crop depends on exposure of the crop to droughts and the propensity of the exposed crop to droughts. Therefore, the drought risk to crops can be defined as,

$$
\text { Risk }=\text { Hazard } \times \text { Vulnerability } \times \text { Exposure, }
$$

Vulnerability is hazard-specific, such as tolerance of crop to droughts (water stress), and floods (excess of water) are different. Vulnerability of crops to drought depends on their tolerance to water stress. Zhang et al. [42] reviewed the impacts of droughts on wheat yields from 60 published studies and rice yields from 55 studies. They reported that drought affects rice and wheat differently during growth stages. However, the overall impacts of droughts on wheat and rice yields are more or less the same. It caused a decrease in wheat yield by $27.5 \%$ and rice by $25.4 \%$. It indicates that vulnerability of wheat and rice to droughts is the same. As the vulnerability of different crops to drought is constant, it was not considered for the development of risk maps. Therefore, the drought risk to crops was estimated from probability of occurrence of droughts and the exposure of crops to droughts,

$$
\text { Risk }=\text { Hazard } \times \text { Exposure, }
$$

A weighted overlay index method was used in this study to assess hazard and exposure. Catastrophe theory [43] fuzzy membership functions were used to derive weights for this purpose. Four steps were used for this purpose: (a) establishment of sub-systems, (b) derivation of indicators, (c) standardization of indicator values, and (d) application of catastrophe models for normalization. Finally, drought risk to crops was computed from hazard and exposure. The steps are discussed below in details.

\subsubsection{Sub-Systems of Hazard and Exposure}

The catastrophe multi-criteria evaluation method draws on the analytic hierarchy of catastrophe theory, and thus considered subject matter as a system which is divided into several subsystems with different evaluation indicators according to the inner mechanisms of the system being assessed $[26,30,33]$. Following the analytical hierarchy of catastrophe theory, drought hazard and crop exposure to droughts were considered as two individual systems in this study. The drought hazard system was considered as composed of three sub-systems according to different frequencies of droughts during crop growing seasons, namely 10-, 50-, and 100-year return period droughts. Different return periods of droughts have different characteristics in terms of areal extents and intensity. Ahmed et al. [12] reported that areal extent of higher return period droughts is greater compared to lower return periods. The intensity of the higher return period of droughts is also greater compared to the lower return period. Therefore, different return periods of droughts were taken into consideration in defining drought hazard. A 10-year return period droughts or occurrence of droughts once in a decade indicates recurrent droughts, while 50- and 100-year return periods indicate less frequent and rare occurrence of droughts, respectively. Alamgir et al. [6] reported that the spatial characteristics of 
droughts in Bangladesh for those return periods vary widely for different seasons. Therefore, those return periods were selected for the estimation of drought hazards during different crop growing seasons. The system of crop exposure was considered to have two sub-systems-total cultivated area of the crop and yield of the crop per hectare. The effect of droughts on crops is greater if the cultivated area and crop yield is greater. Therefore, those two were considered as the sub-systems that define crop exposure.

\subsubsection{Classification of Indicators of Sub-Systems}

Data of each sub-system was used to derive indicators. Drought severity (SPI values) of different return periods of droughts were used to derive indicators of different sub-systems of drought hazard. The cultivated area and crop yield values in different sub-districts of Bangladesh were used to derive indicators of the two sub-systems of crop exposure.

The standardized precipitation index (SPI) estimated for the last month of a cropping season with a time-step equal to the span of the season in months was used to estimate drought in the season. For example, the HYV Aus is grown during May to November (6 months period). Therefore, 6-month SPI estimated in the month of November was considered as droughts during HYV Aus growing season. The droughts estimated using this procedure can have a single value for each year. Therefore, the return period of droughts for a cropping season with particular severity can be calculated as the inverse of its probability of occurrence in a year. SPI values less than -0.5 of a season were fitted with the most suitable probability distribution function (PDF) for the estimation of the return periods of droughts (SPI values). The years without droughts (SPI $\geq-0.5$ ) were assigned a value of zero and frequency analysis was conducted for the SPI values less than -0.5. All the SPI values less than -0.5 were fitted using distribution function in order to estimate the intensities of different return periods of droughts. Obtained frequency (F) was corrected to account for the zero values [2],

$$
F^{\prime}=q+(1-q) F
$$

where $q$ is the probability of zero values. The return period was finally estimated from the corrected frequency. Details of the calculation of the return period of seasonal SPI can be found in $[2,5,6,44]$.

In the present study, 10-, 50-, and 100-year return period SPI values for each crop were estimated at each station. Kriging method was used for interpolation of SPI values for mapping different return periods of droughts. Justification of using kriging for interpolation of SPI in Bangladesh can be found in [6]. In order to produce the district scale drought hazard maps, the overlaying of the drought hazard maps on the Bangladesh district map was conducted. The obtained maps were overlaid on the district map of Bangladesh to generate a district scale drought hazard map using area weighted overlay method [44].

The SPI values for different return periods were decomposed into number of levels using Jenks optimization method to derive indicators. The number of indicators and the data range of the indicators can change the weight of a sub-system significantly [45]. Jenks method [46] divides data in an optimum way so that the variance among data within a class is minimal, but the variance among the mean values of data in different classes is maximal. It classifies data based on inherent properties of data without any user interference, and thus reduces subjectivity in decision making [46]. Besides, Jenks optimization is better suited to classify data into small number of groups. The maximum control variable that can be used in catastrophe models is limited to 5 . Therefore, Jenks method can be a suitable option to be used with catastrophe models for derivation of indicators. The indicators were derived according to the natural variability of sub-system data and then used to estimate the weight of the sub-systems. 


\subsubsection{Standardization of Data}

A linear standardization approach was used to make the indicators dimensionless in order to eliminate the influence of different indicators in computation of weight. Lower values of SPI indicate higher severity of droughts, while higher values of crop cultivated area and crop yield indicate more exposure. Therefore, two different formulas were used for data standardization in a range between 0 and 1 . The SPI values for different return periods were standardized as,

$$
x_{i}^{\prime}=\frac{x_{i(\max )}-x_{i}}{x_{i(\max )}-x_{i(\min )}}
$$

The crop cultivated area and crop yield data were standardized as,

$$
x_{i}^{\prime}=\frac{x_{i}-x_{i(\min )}}{x_{i(\max )}-x_{i(\min )}}
$$

where $x_{\mathrm{i}}$ is the mean value of indicator $i$; and $x_{\mathrm{i}(\max )}$ and $x_{\mathrm{i}(\min )}$ are the maximum and minimum values of the indicator $i$.

\subsubsection{Normalization of Indicators Using Catastrophe Models}

Catastrophe theory considers the subject matter as a system consisting of several subsystems. It assesses the changes in the state of the system with the changes of the variables that control the system, i.e., sub-systems. For example, the state of crop exposure system is controlled by two subsystems-total cultivated area of the crop and yield of the crop per hectare. In the catastrophe method, the relationship of state variable with control variables is determined by catastrophic fuzzy membership functions. Catastrophe models were used to normalize the standardized values of the indicators (obtained using Equations (4) and (5)) to resolve the incompatibility among the standardized data [31]. The catastrophe models were used for the estimation of a single index, e.g., drought hazard or exposure. Therefore, five catastrophe models having one state variable, as listed in Table 2, were used in this study. The normalization formulas of the five catastrophe models are also given in Table 2.

Table 2. Normalization formulas of the catastrophe models.

\begin{tabular}{cccc}
\hline Control Variable & State Variable & Model Name & Normalization Formula \\
\hline 2 & 1 & Cusp & $x_{a}=a^{1 / 2}$ and $x_{b}=b^{1 / 3}$ \\
3 & 1 & Swallowtail & $x_{a}=a^{1 / 2} ; x_{b}=b^{1 / 3}$ and $x_{c}=c^{1 / 4}$ \\
4 & 1 & Butterfly & $x_{a}=a^{1 / 2} ; x_{b}=b^{1 / 3} ; x_{c}=c^{1 / 4}$ and $x_{d}=d^{1 / 5}$ \\
5 & 1 & Wigwam & $x_{a}=a^{1 / 2} ; x_{b}=b^{1 / 3} ; x_{c}=c^{1 / 4} ; x_{d}=d^{1 / 5}$ and $x_{e}=e^{1 / 6}$ \\
\hline
\end{tabular}

Catastrophe models can be used for a maximum of five control variables. Therefore, Jenks optimization was allowed to classify the sub-system data into a maximum of five classes. The method classified the sub-system data into 2 to 5 indicators according to inherent characteristics of the data. The weight of a sub-system was estimated using different catastrophe models depending on the number of indicators of the sub-system. For example, the Swallowtail normalization formula was used when the number of indicators was three.

where $a, b, c, d$, and e are the mean values of ranges of an indicator and $x_{a}, x_{b}, x_{c}, x_{d}$, and $x_{e}$ are the normalized values.

\subsubsection{Estimation of Drought Risk Index}

The general procedure used for the estimation of drought risk to crops is outlined below:

1. The drought risk to crops was considered as a product of drought hazard (severity and frequency) during a cropping season and exposure of crops to drought; 
2. The drought hazard and exposure were considered as two systems, each consisting of a number of sub-systems;

3. The data of each sub-system were classified using a Jenks optimization algorithm to obtain the indicators of the sub-system;

4. The mean of each indicator was standardized into a dimensionless number in the range of 0 to 1 which were considered as the rank;

5. The catastrophe model was then used to estimate the normalized value of fuzzy membership function from the standardized values, which was considered as the weight of the sub-system;

6. The drought hazard and exposure were estimated using Equations (6) and (7), respectively.

$$
\begin{gathered}
\text { Hazard } \left.=\left(\left(\mathrm{D} 10_{\mathrm{w}} \times \mathrm{D} 10_{\mathrm{r}}\right)+\left(\mathrm{D} 25_{\mathrm{w}} \times \mathrm{D} 25_{\mathrm{r}}\right)+\left(\mathrm{D} 100_{\mathrm{w}} \times \mathrm{D} 100_{\mathrm{r}}\right)\right) /\left(\mathrm{D} 10_{\mathrm{w}}+\mathrm{D} 25_{\mathrm{w}}+\mathrm{D} 100_{\mathrm{w}}\right)\right) \\
\text { Exposure }=\left(\left(\mathrm{A}_{\mathrm{w}} \times \mathrm{A}_{\mathrm{r}}\right)+\left(\mathrm{Y}_{\mathrm{w}} \times \mathrm{Y}_{\mathrm{r}}\right)\right) /\left(\mathrm{A}_{\mathrm{w}}+\mathrm{Y}_{\mathrm{w}}\right)
\end{gathered}
$$

where $\mathrm{w}$ refers to weight, $\mathrm{r}$ refers to rank, D10, D25, and D100 represent the return periods of 10-, 25-, and 100-year droughts, $A$ refers to cultivated area, and $Y$ represents crop yield.

\section{Result and Discussion}

\subsection{Seasonal Drought Hazard}

Drought hazards during different crop growing seasons were investigated based on return periods of 10, 50, and 100 years. As the major crops are grown during the Kharif, Rabi, and pre-Kharif seasons in Bangladesh, drought hazards during these three seasons were estimated. Preparation of drought hazard maps during Kharif season are discussed here as an example. The spatial patterns of the 10-, 50-, and 100-year return period SPI values during Kharif season are presented in Figure 2a-c. The SPI values estimated for a particular return period at different stations were interpolated and then intercepted with the Bangladesh district map to measure the drought hazard of each district using the area-weighted average method. Using the Jenks classification scheme, different classes of the SPI or indicators of each sub-system were obtained. This produced different number of indicators for different sub-systems of drought hazard. For example, the 10-year return period SPI values in Kharif season were classified into two indicators: -0.5 to -1.38 and -1.39 to -2.00 . Four indicators were used for the 50-year return period Kharif drought: -0.5 to $-1.42,-1.43$ to $-2.44,-2.45$ to -3.11 , and -3.12 to -3.99 . Lastly, two indicators were used for the 100-year return period drought: -2.68 to -2.86 and -2.87 to -3.2 .

The mean value of each indicator was calculated and standardized to estimate the ranks. The ranks were then used to estimate the weight of the sub-system using catastrophe theory. The results of Kharif drought are elaborated in Table 3. The mean SPI values of each category of droughts are given in the third column of Table 3. The values were used to calculate the rank for each category of droughts of a particular return period and to derive weights of that particular drought return period using catastrophe theory. For example, there are four indicators of Kharif 50-year return period droughts. Therefore, Butterfly model was used for estimation of weight. The standardized values are normalized using Butterfly model as, $x_{a}=a^{1 / 2}=(0)^{1 / 2}=0 ; x_{b}=b^{1 / 3}=(0.376)^{1 / 3}=0.0532 ; x_{c}=$ $c^{1 / 4}=(0.701)^{1 / 4}=0.2415$; and $x_{d}=d^{1 / 5}=(1)^{1 / 5}=1$. The weight was calculated as the average of normalized value, $(0.0+0.0532+0.2415+1) / 4=0.545$. Similarly, weights of other sub-systems were calculated. Obtained values of ranks and weights are given in the fourth and fifth columns of Table 3. 


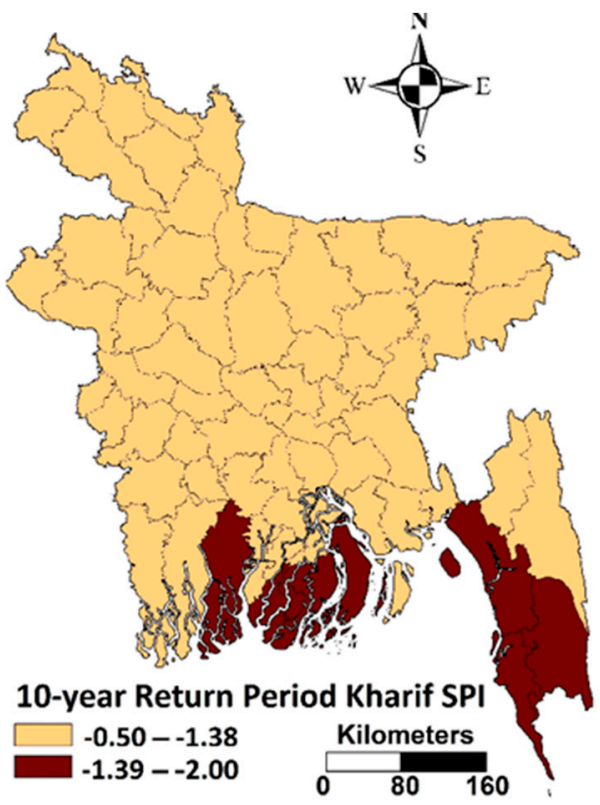

(a)

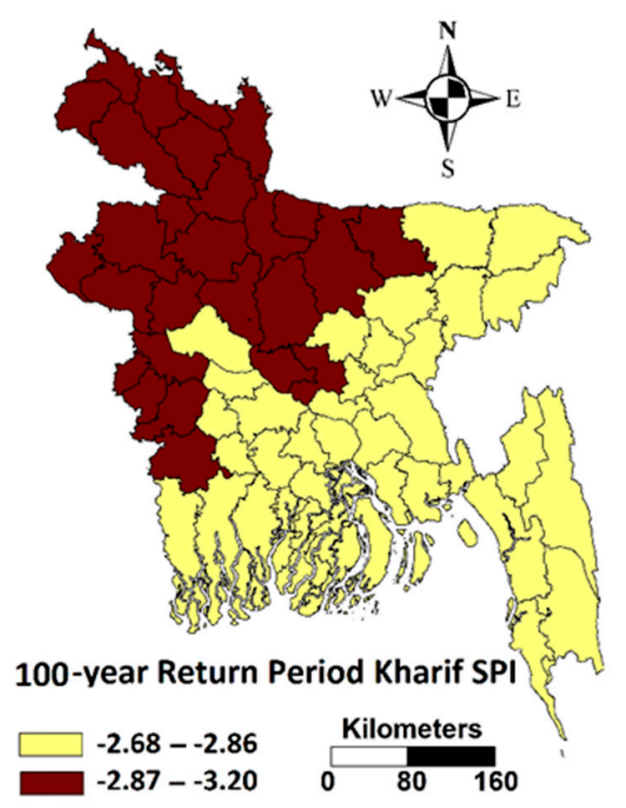

(c)

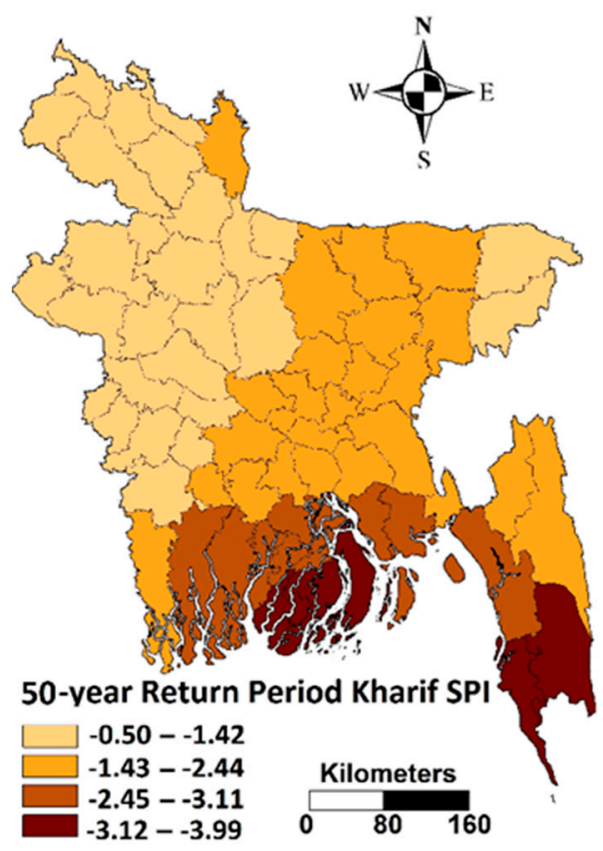

(b)

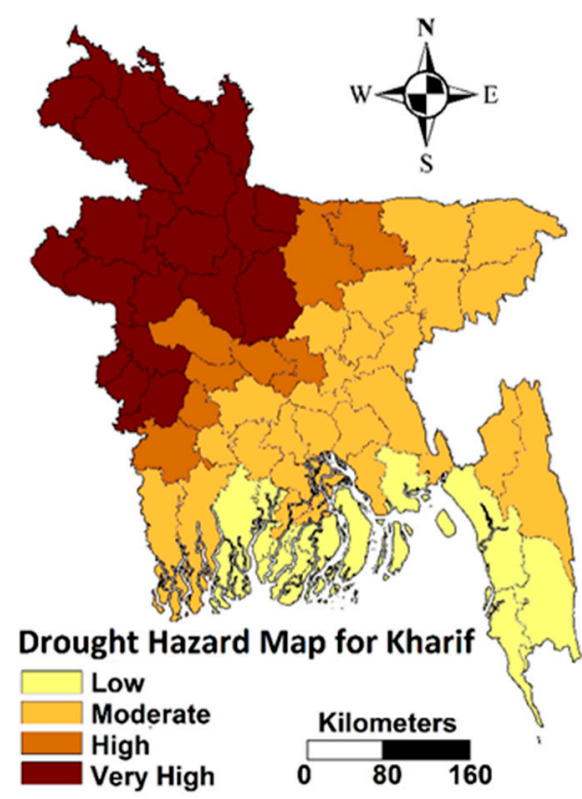

(d)

Figure 2. Kharif drought severity with (a) 10-, (b) 50-, and (c) 100-year return periods, and (d) the drought hazard map generated using Catastrophe weighting method. 
Table 3. Calculation of weight and ranks of Kharif drought.

\begin{tabular}{ccccc}
\hline Sub-System & Indicators (SPI) & Mean Value & Rank & Weight \\
\hline Kharif 100-year & $-2.68--2.86$ & -2.770 & 0 & 0.5 \\
return period & $-2.87--3.20$ & -3.035 & 1 & \\
\hline & $-0.50--1.42$ & -0.960 & 0 & 0.545 \\
Kharif 50-year & $-1.43--2.44$ & -1.935 & 0.376 & \\
return period & $-2.45--3.11$ & -2.780 & 0.701 & \\
& $-3.12--3.99$ & -3.555 & 1 & 0.5 \\
\hline Kharif 10-year & $-0.50--1.38$ & -0.940 & 0 & \\
return period & $-1.39--2.00$ & -1.695 & 1 & \\
\hline
\end{tabular}

The calculated ranks and weights were used to prepare the Kharif drought hazard maps of Bangladesh using Equation (6). The estimated hazard index was classified into four groups and named as low, moderate, high, and very high to prepare the map of Kharif drought hazard, as shown in Figure $2 \mathrm{~d}$. The figure reveals that droughts during Kharif season are more apparent in the northwestern part of Bangladesh.

Drought hazard maps for Rabi and pre-Kharif seasons were prepared in a similar way. Areas affected by different seasonal droughts are shown in Figure 3. Results show about $32.4 \%$ area of Bangladesh is prone to Kharif drought of very high severity, about $10.0 \%$ experiences Kharif drought of high severity, $41.8 \%$ area faces moderate drought, and the remaining $15.8 \%$ area experiences only low Kharif droughts. On the other hand, about $27.2 \%$ area of Bangladesh is found to experience Rabi drought of very high severity, 31.6\% high severity, $27.2 \%$ moderate severity, and the remaining $14.1 \%$ experiences low severity Rabi drought. Affected area by very-high severity pre-Kharif drought is found to be less (13.2\%) compared to Kharif and Rabi droughts. About $47.5 \%$ of the area of Bangladesh is affected by moderate severity of pre-Kharif drought and $30.0 \%$ area by high severity pre-Kharif drought.

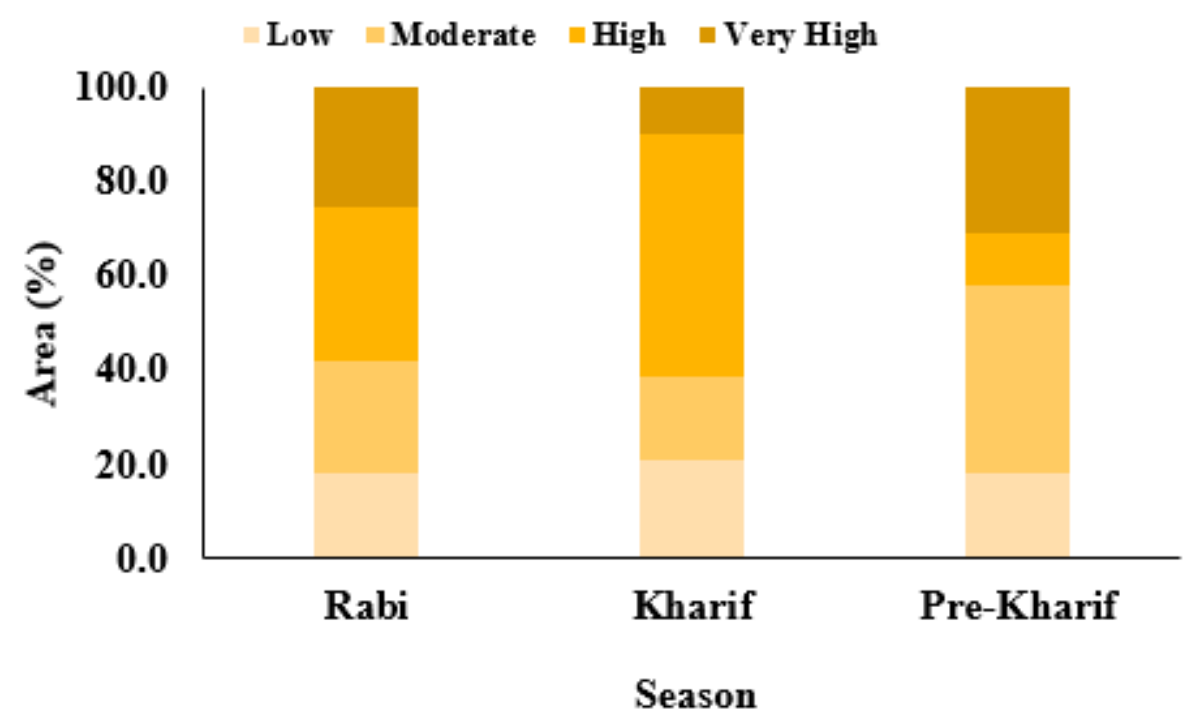

Figure 3. Drought hazard during Rabi, Kharif, and pre-Kharif seasons.

\subsection{Drought Exposure}

Each of these two sub-systems of drought exposure was classified into different classes (indicator) on the basis of the Jenks natural break classification scheme. The calculation of ranks and weights of cultivated area and crop yield for $\mathrm{L}$ Aus rice is elaborated in Table 4, as an example. Both the cultivated area and yield of L Aus rice was classified into four classes by Jenks optimization. Therefore, the weights of yield and area were calculated by using Butterfly Catastrophe formula. Average values 
for each class are given in the third column of Table 4. The values were used in calculating the ranks for each category of cultivated area or crop yield, as well as the weight of crop yield and cultivated area using catastrophe theory. Obtained values of ranks and weights are given in the fourth and fifth columns of Table 4 . These numbers indicate that the crop yield has a larger influence on exposure compared to the cultivated area of that crop. Calculated weights and ranks were used to estimate exposure of crops to drought using Equation (7). District scale maps of cultivated area, crop yield, and drought exposure of L Aus rice is shown in Figure 4, as an example.

Table 4. Calculation of weight and ranks of Local Aus (L Aus) rice.

\begin{tabular}{ccccc}
\hline Sub-System & Indicators & Mean Value & Rank & Weight \\
\hline & $19420-46447$ & 32933 & 1 & \\
Area & $9532-19419$ & 14475 & 0.409 & 0.267 \\
(L Aus Rice) & $3327-9531$ & 6428 & 0.152 & \\
& $0-3326$ & 1663 & 0 & \\
& $1.30-1.66$ & 1.47 & 1 & 0.353 \\
Yield & $0.99-1.29$ & 1.13 & 0.730 & \\
(L Aus Rice) & $0.44-0.98$ & 0.7 & 0.389 & 0 \\
\hline
\end{tabular}

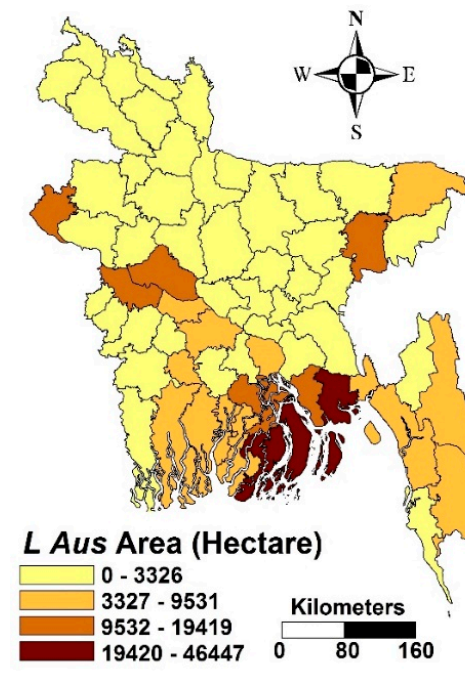

(a)

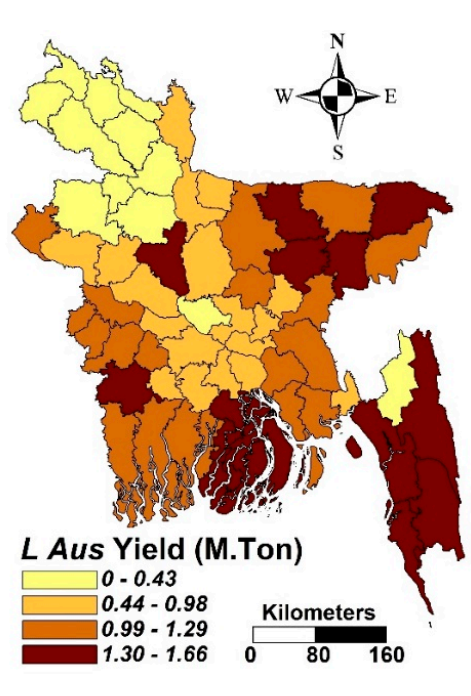

(b)

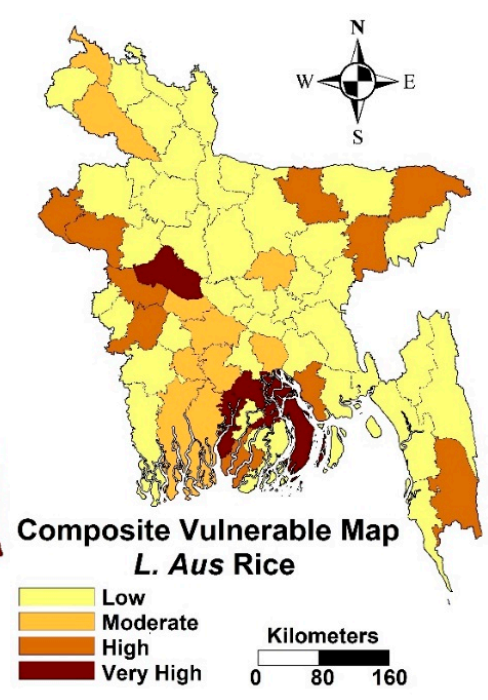

(c)

Figure 4. District level maps of (a) L Aus cultivated area, (b) L Aus yield, and (c) drought exposure of L Aus Rice.

Figure 4a shows that $\mathrm{L}$ Aus rice is mostly cultivated in districts located in the south and south-east parts of Bangladesh. The yield of L Aus rice (Figure $4 \mathrm{~b}$ ) is also high in those districts along with other districts located in eastern Bangladesh. Therefore, the drought exposure of $L$ Aus rice to drought was also found to be very high in southern coastal districts. Besides that, high exposure of $\mathrm{L}$ Aus rice to drought was found in some other districts sporadically distributed over the country.

Exposure maps to droughts for other crops were prepared in a similar way. The maps were analyzed to estimate the exposed areas of different crops to droughts. Figure 5 shows the exposure of crops to droughts. It shows that the most exposed crop to droughts in Bangladesh is the HYV Aman rice. The HYV Aman rice cultivated in $18.1 \%$ of the country is highly exposed to droughts. This is followed by H Boro (17.8\%), HYV Boro (10.7\%), HYV Aus (7.2\%), Wheat (7.0\%), and L Aus (5.5\%). Among the crops considered in this study, potato is found to be the least exposed to droughts. It was 
found that potato cultivated in $79 \%$ of the country is of low exposure. This is followed by L Boro (62.3\%), wheat (59.6), T Aman (59.2\%), and L Aus (59.1\%).

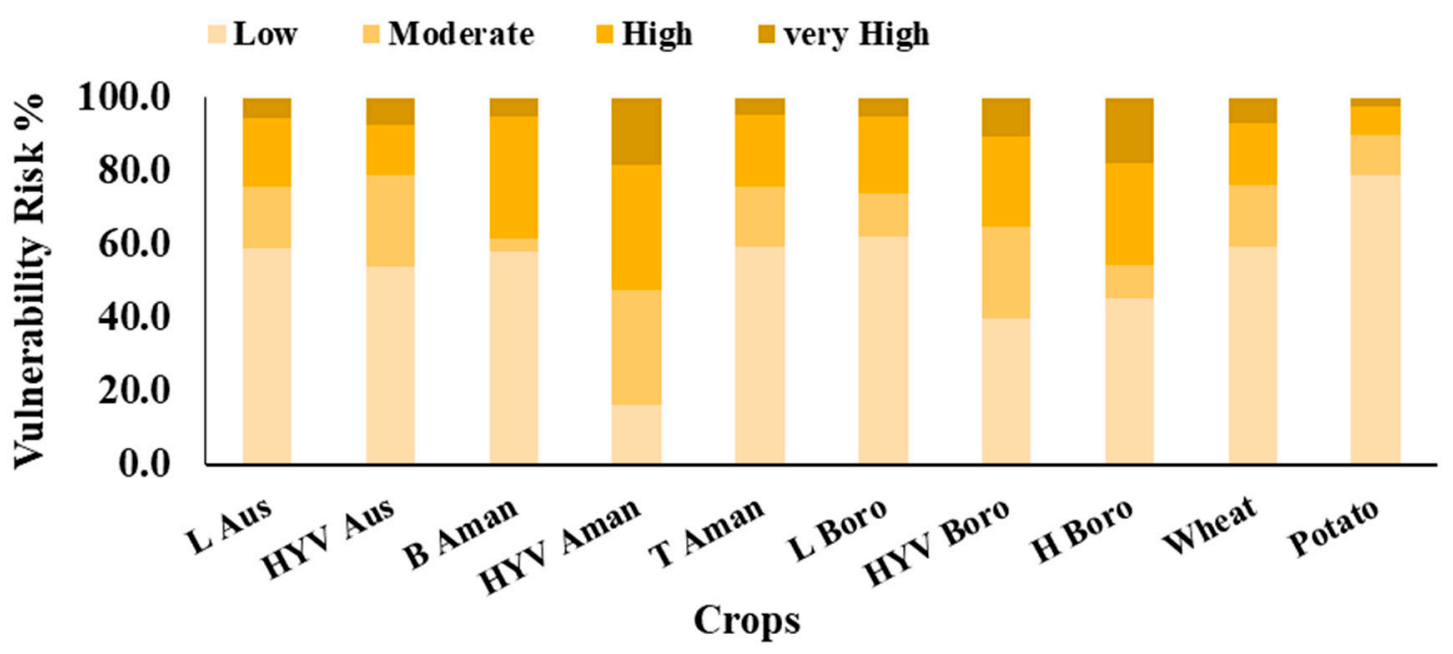

Figure 5. Composite vulnerability of crops to drought.

\subsection{Drought Risk to Crop}

The drought hazard and exposure maps were integrated using Equation (7) to prepare the drought risk map for crops. The exposure map of a particular crop was integrated with the drought hazard map of the season when it is grown, following the crop calendar shown in Table 1. For example, the crops B. Aman, HYV Aman, and T Aman were integrated with the drought hazard map of Kharif season. The drought risk maps of different crops are shown in Figure 6.

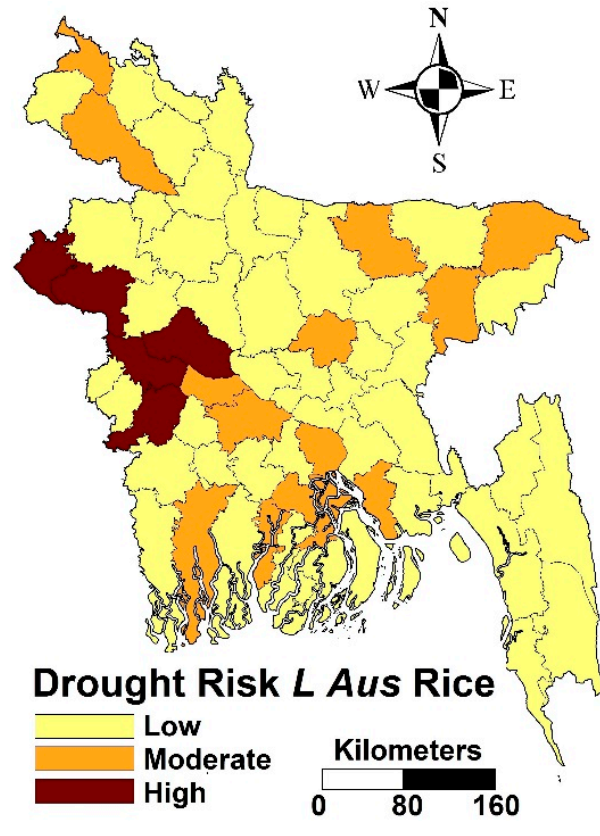

(a)

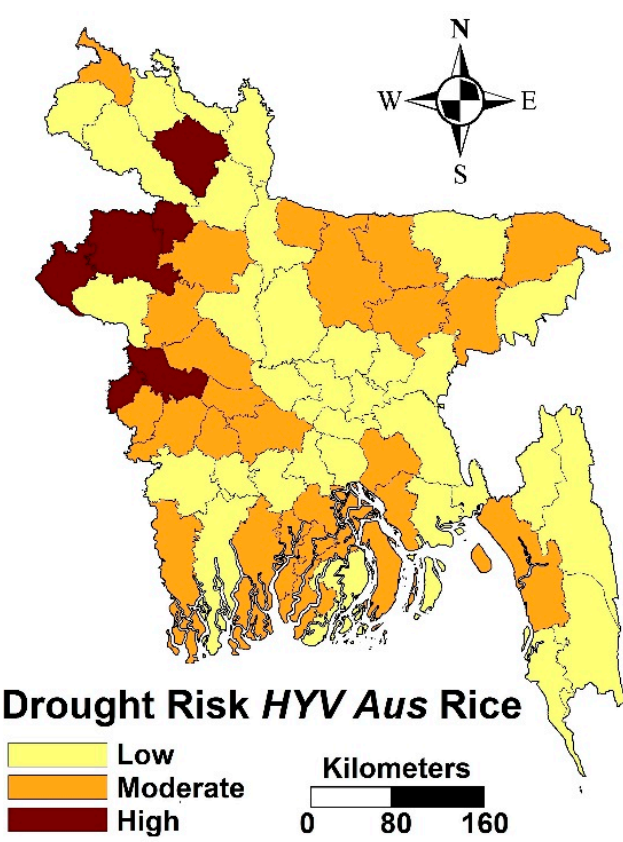

(b)

Figure 6. Drought Risk Map of (a) L Aus and (b) HYV Aus grown during Kharif.

Figure 6a,b shows L Aus and HYV Aus crops are grown during Kharif season, which poses high drought risk in only a few areas of northwest Bangladesh. However, both crops were found to have moderate risk in some other regions, like southern and eastern parts of Bangladesh. 
Drought risk maps of T Aman and HYV Aman rice grown during monsoon are presented, respectively, in Figure 7a,b. It shows that $\mathrm{T}$ Aman rice is highly prone to drought in most parts of the country. On the other hand, the HYV Aman rice is highly exposed to drought risk in the north and northwestern parts of the country.

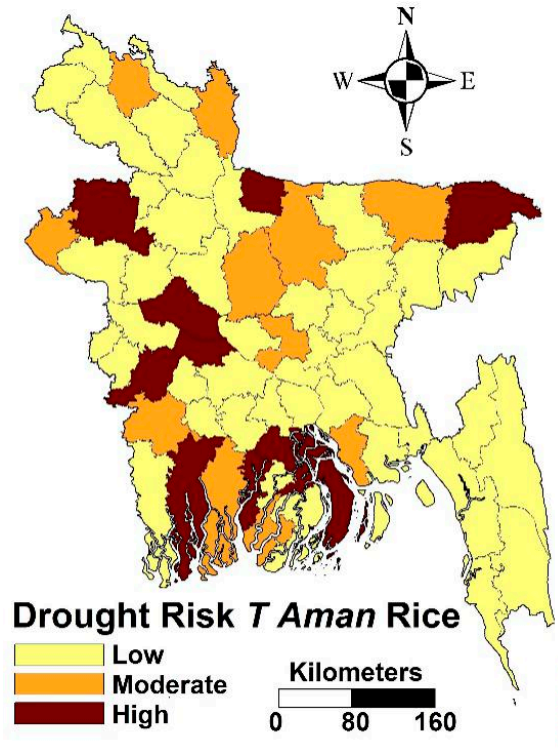

(a)

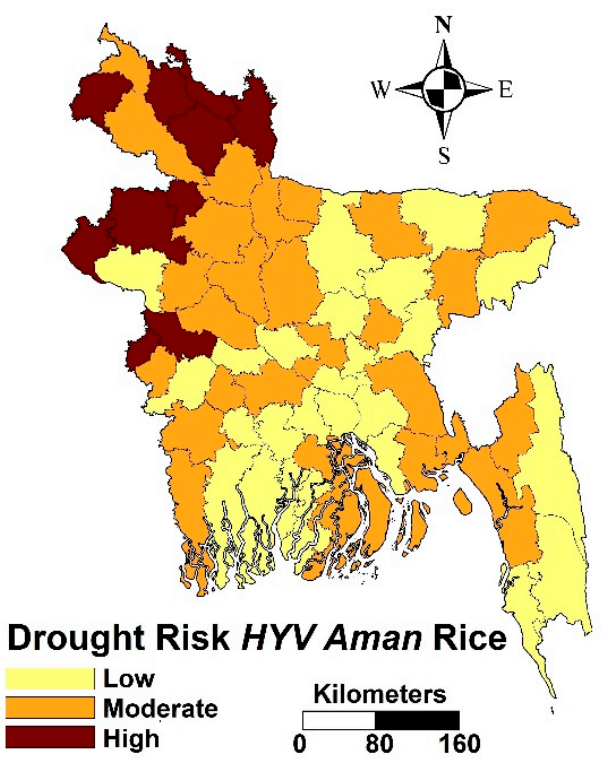

(b)

Figure 7. Drought Risk Map of (a) T Aman and (b) HYV Aman grown during monsoon season

Figure $8 \mathrm{a}$, b shows the drought risk to HYV Boro rice and $\mathrm{H}$ Boro rice in Bangladesh, which are mostly grown during pre-Kharif season. Both maps show that HYV Boro rice and H Boro rice are exposed to high droughts risks in the north and northwestern parts of the country. The HYV Boro rice faces moderate risk to droughts in the central part of the country.

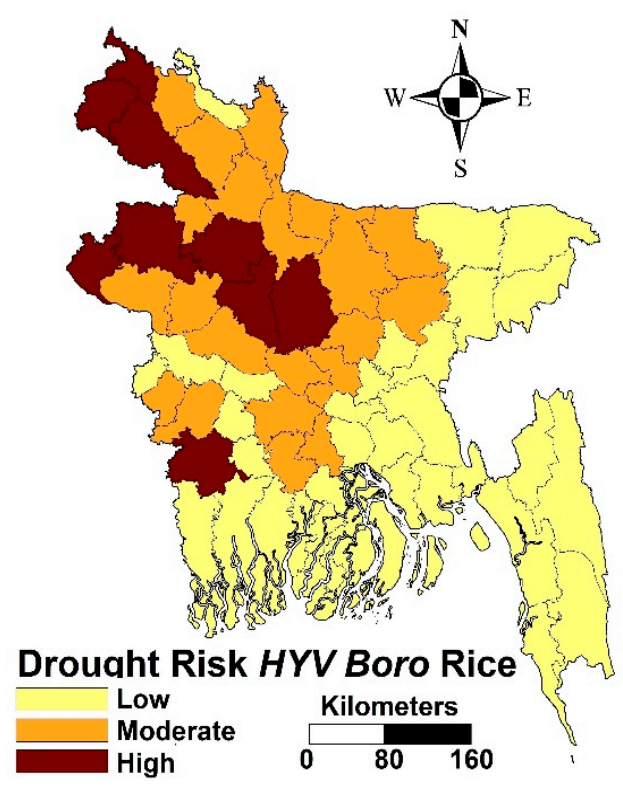

(a)

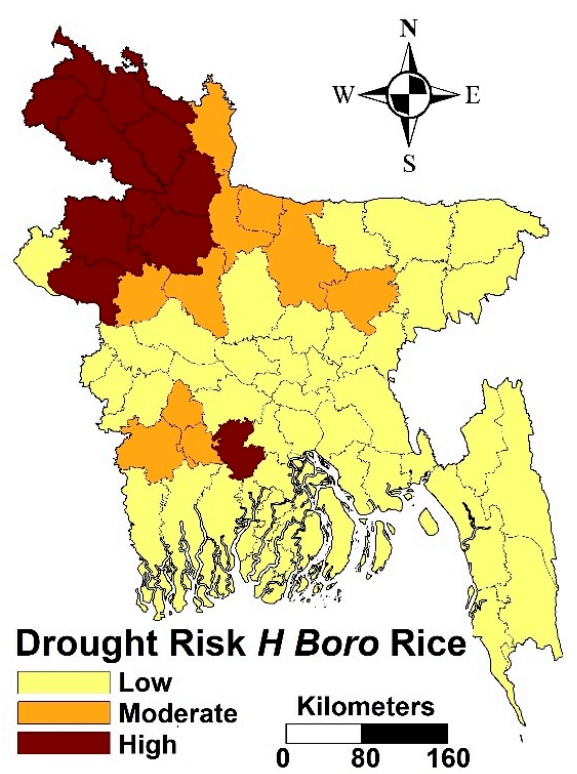

(b)

Figure 8. Drought Risk Map of pre-Kharif season (a) HYV Boro and (b) H Boro 
The drought risk maps of L Boro and B Aman rice grown during Rabi seasons are presented, respectively, in Figure 9a,b. Figure 10a shows that drought risk to L Boro rice is sparsely distributed over the country. The drought risk to this crop is found only in 4 out of 64 districts of Bangladesh. A similar pattern was found in drought risk to B Aman rice (Figure 9b).

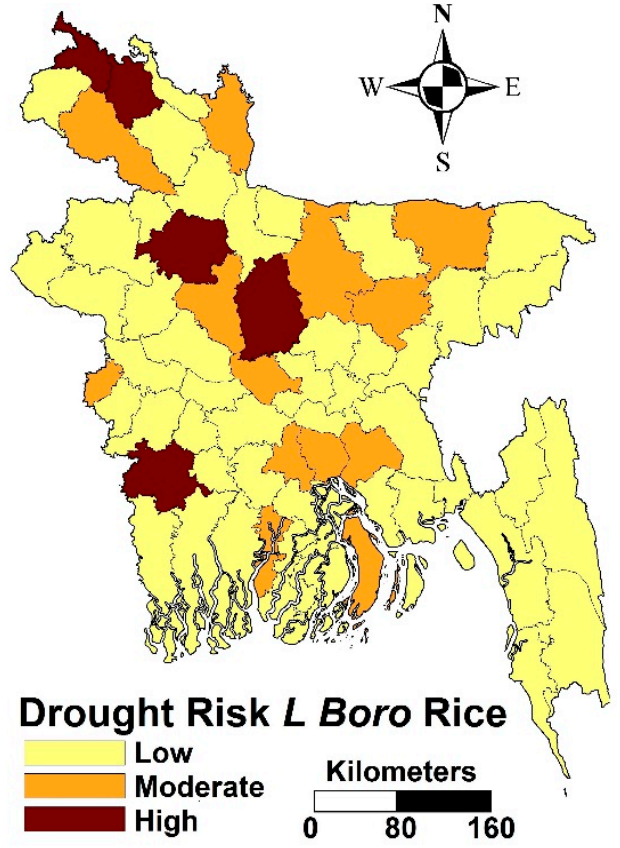

(a)

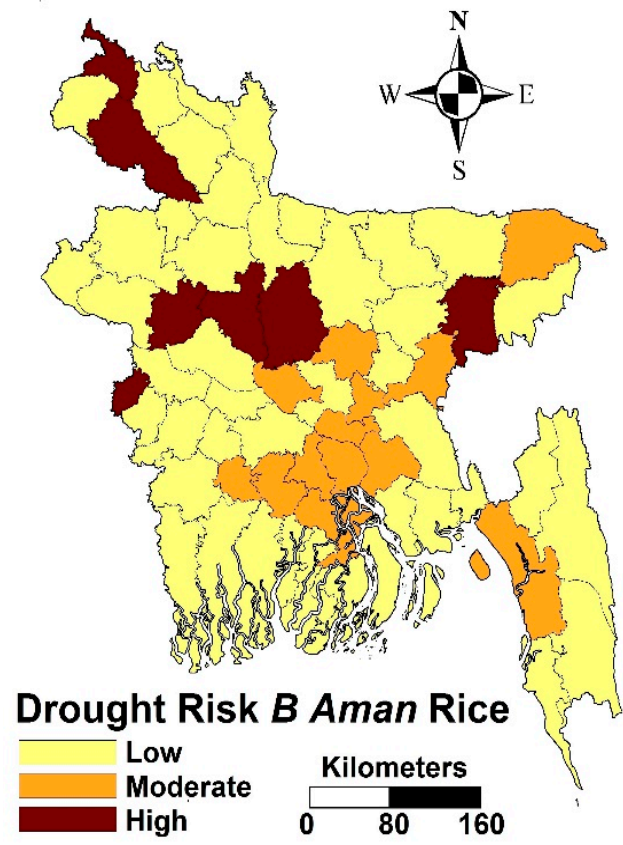

(b)

Figure 9. Drought Risk Map of Rabi (Winter) season (a) L Boro and (b) B Aman

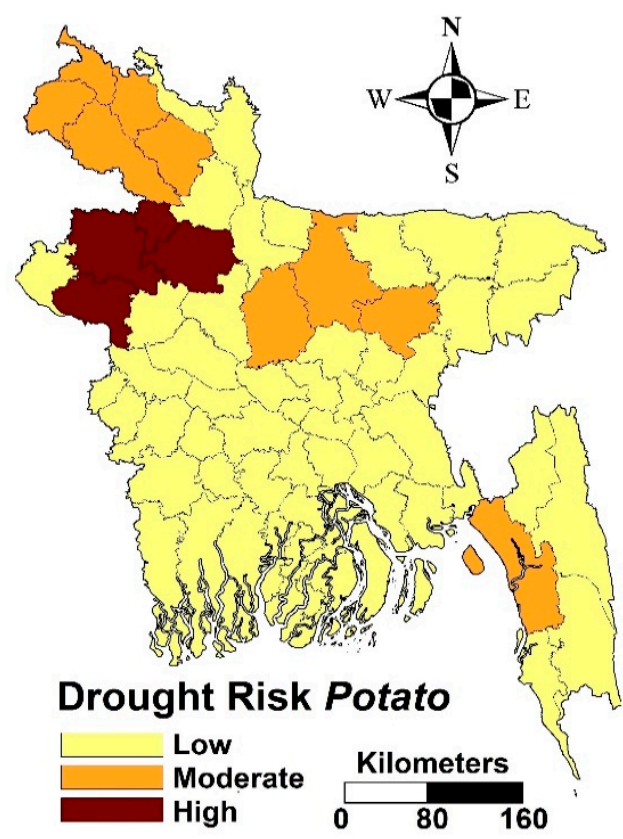

(a)

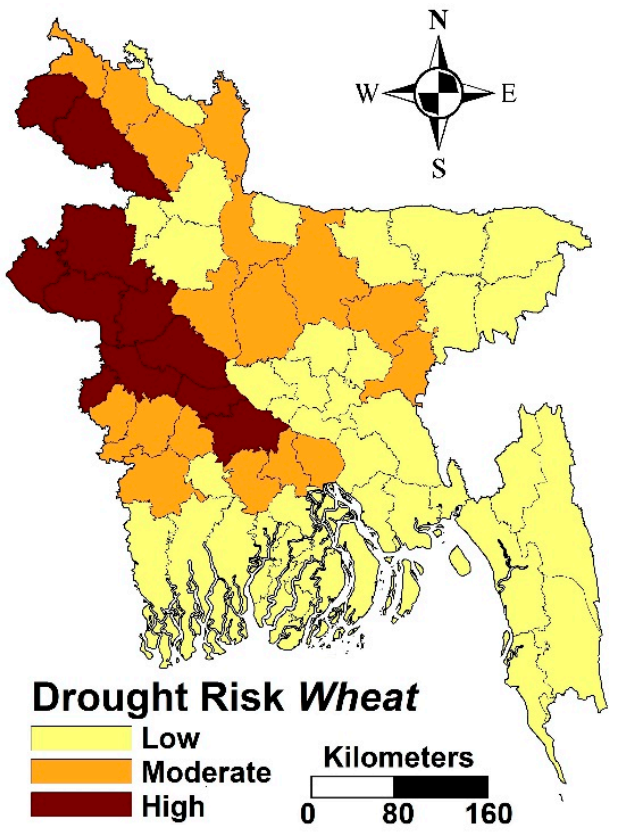

(b)

Figure 10. Drought Risk Map of Rabi (Winter) season (a) potato and (b) wheat. 
The drought risk to potato and wheat, which are grown during winter season, are presented in Figure 10a,b, respectively. High drought risk to potato was found only in four districts located in northwest Bangladesh. On the other hand, high drought risk to wheat was found in most northwest districts as well as a few northern and central districts of Bangladesh.

These maps were analyzed to assess the risk of different crops to droughts in Bangladesh. The results (Figure 11) show that drought risk is highest for T Aman rice. The T Aman rice cultivated in $18.1 \%$ of the country faces high risk to droughts. This follows H Boro (17.8\%), wheat $(17.1 \%)$, and HYV Boro (12.6\%). Among all crops considered in this study, risk of L Aus to droughts was found to be the least in Bangladesh.

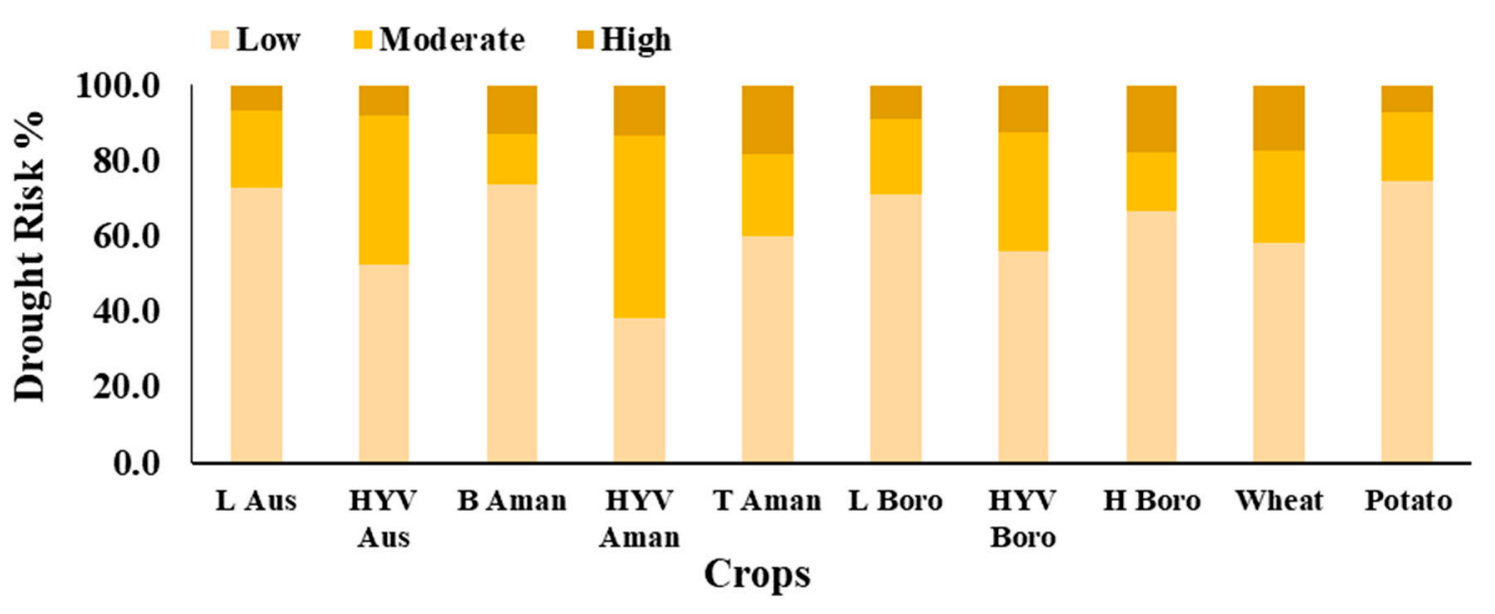

Figure 11. Drought risk of crop over study area.

\section{Conclusions}

The spatial distribution of drought risk to major crops of Bangladesh is assessed in this study. The seasonal drought hazards were estimated during different crop growing seasons using frequency analysis of SPI values. The exposure of crops to droughts was estimated based on crop-cultivated land and crop productivity. Finally, the seasonal drought hazard map was integrated with the crop exposure map to prepare the map of drought risk to crops. This study has the novelty of using droughts in different crop growing seasons in estimating drought risk, catastrophe theory in assessing weighting of different themes, and ranks of different features of each theme to avoid potentially biased human judgment in risk assessment.

It was found that $\mathrm{T}$ Aman rice cultivated during Kharif season is exposed to the highest risk of drought in Bangladesh, which is followed by wheat, H Boro, HYV Boro, HYV Aus, wheat, and L Aus. On the other hand, potato is found to be least exposed to droughts risk, followed by B Aman and L Boro rice. The spatial distribution of droughts risk to major crops in Bangladesh reveals that crops cultivated in the country's northwestern part are the most droughts prone, followed by northern part of the country. Generally, the north and the northwest regions of the country are more susceptible to droughts, and crop damage due to droughts in these regions has been reported several times. Therefore, the overall results of this study correspond with the general conception of drought risk in Bangladesh.

Crop exposure to drought depends on many other factors, such as availability of irrigation facility, surface, and groundwater resources. Studies can be conducted in the future to prepare the exposure map by considering all these factors. Drought hazard was estimated in this study using SPI, which only considers rainfall as a climatic variable. However, temperature is an influential factor to define droughts, particularly in tropical regions. Therefore, it can be considered in the future to measure drought hazard in Bangladesh. In this study, drought risk to crops was assessed based on easily available data. It is envisaged that the method presented in this study be used for rapid and unbiased 
estimation of drought risk to crops. The maps generated here are crucial for adaptation planning and mitigation of increased severity and frequency of droughts predicted due to climate change.

Author Contributions: Conceptualization, M.A., M.M., X.W., S.S., and N.E.A.; data curation, R.H. and M.S.S.; investigation, M.M.; writing—original draft, M.M., X.W. and A.Y.; writing—review and editing, X.W. and S.S.

Funding: This research was funded by Young Top-Notch Talent Support Program of National High-level Talents Special Support Plan and Malaysia-Japan International Institute of Technology (MJIIT) - Universiti Teknologi Malaysia (grant number 4J282).

Acknowledgments: We thankful to anonymous reviewers and editors for their helpful comments and suggestions.

Conflicts of Interest: The authors declare no conflict of interest.

\section{References}

1. Wang, X-J.; Zhang, J.-Y.; Shahid, S.; ElMahdi, A.; He, R.-M.; Zhen-xin, B.; Ali, M. Water resources management strategy for adaptation to droughts in China. Mitig. Adapt. Strat. Gl. 2012, 17, 923-937.

2. Mohsenipour, M.; Shahid, S.; Chung, E.-S.; Wang, X.-J. Changing Pattern of Droughts during Cropping Seasons of Bangladesh. Water Resour. Manag. 2018, 32, 1555-1568. [CrossRef]

3. Shiru, M.S.; Shahid, S.; Alias, N.; Chung, E.S. Trend analysis of droughts during crop growing seasons of Nigeria. Sustainability 2018, 10, 871. [CrossRef]

4. Shahid, S.; Hazarika, M.K. Groundwater drought in the northwestern districts of Bangladesh. Water Resour. Manag. 2010, 24, 1989-2006. [CrossRef]

5. Ahmed, K.; Shahid, S.; Harun, S.b.; Wang, X.-j. Characterization of seasonal droughts in Balochistan Province. Pakistan. Stoch. Environ. Res. Risk. Assess. 2016, 30,747-762. [CrossRef]

6. Alamgir, M.; Shahid, S.; Hazarika, M.K.; Nashrrullah, S.; Harun, S.B.; Shamsudin, S. Analysis of Meteorological Drought Pattern During Different Climatic and Cropping Seasons in Bangladesh. J. Am. Water. Resour. Assoc. 2015, 51, 794-806. [CrossRef]

7. Sung, J.; Chung, E.S.; Shahid, S. Reliability-Resiliency-Vulnerability Approach for Drought Analysis in South Korea Using 28 GCMs. Sustainability 2018, 10, 3043. [CrossRef]

8. Ahmed, K.; Shahid, S.; Nawaz, N. Impacts of climate variability and change on seasonal drought characteristics of Pakistan. Atmos. Res. 2018, 214, 364-374. [CrossRef]

9. Damania, R.; Desbureaux, S.; Hyland, M.; Islam, A.; Moore, S.; Rodella, A.-S.; Russ, J.; Zaveri, E. Uncharted Waters; World Bank: Washington, DC, USA, 2017.

10. Cai, X.; Zeng, R.; Kang, W.H.; Song, J.; Valocchi, A.J. Strategic planning for drought mitigation under climate change. J. Water Resour. Plann. Manage. 2015, 141, 04015004. [CrossRef]

11. Nasrollahi, M.; Khosravi, H.; Moghaddamnia, A.; Malekian, A.; Shahid, S. Assessment of drought risk index using drought hazard and vulnerability indices. Arab. J. Geoscl. 2018, 11, 606. [CrossRef]

12. Ahmed, K.; Shahid, S.; Chung, E.S.; Wang, X.; Harun, S.B. Climate Change Uncertainties in Seasonal Drought Severity-Area-Frequency Curves: Case of Arid Region of Pakistan. J. Hydrol. 2019, 570, 473-485. [CrossRef]

13. Shahid, S. Spatial assessment of drought hazard, vulnerability and risk in Bangladesh. In Droughts: New Research, 1st ed.; Neves, F.D., Sanz, J.D., Eds.; Nova Science Pub Inc.: New York, NY, USA, 2011; pp. $215-241$.

14. Shahid, S.; Behrawan, H. Drought risk assessment in the western part of Bangladesh. Nat. Hazards. 2008, 46, 391-413. [CrossRef]

15. Karim, Z.; Ibrahim, A.; Iqbal, A.; Ahmed, M. Drought in Bangladesh agriculture and irrigation schedule for major crops; Bangladesh Agricultural Research Center (BARC) Publication No. 34: Dhaka, Bangladesh, 1990.

16. Brammer, H. Drought in Bangladesh: lessons for planners and administrators. Disasters 1987, 11, $21-29$. [CrossRef]

17. Erickson, N.J.; Ahmad, Q.K.; Chowdhury, A.R. Socioeconomic Implications of Climate Change for Bangladesh; Bangladesh Unnayan Parishad: Dhaka, Bangladesh, 1993.

18. Tanner, T.M.; Hassan, A.; Islam, K.N.; Conway, D.; Mechler, R.; Ahmed, A.U.; Alam, M. ORCHID: piloting climate risk screening in DFID Bangladesh; Institute of Development Studies Research Report: Brighton, UK, 2007. 
19. Rasheed, K.B.S. Status of land resource use and desertification, drought and land degradation in Bangladesh: obstacles and effective policy options and measures for sustainable use of land resources. In Proceedings of the National Awareness Seminar on Combating Land Degradation/Desertification, Dhaka, Bangladesh, 5-6 April 1998.

20. World Bank Bangladesh. Water Resource Management in Bangladesh: Steps Towards a New National Water Plan. Report No. 17663-BD; The World Bank Bangladesh: Dhaka, Bangladesh, 1998.

21. Paul, B.K. Coping mechanisms practised by drought victims (1994/5) in North Bengal, Bangladesh. Appl. Geogr. 1998, 18, 355-373. [CrossRef]

22. Shahid, S. Spatial and temporal characteristics of droughts in the western part of Bangladesh. Hydrol. Process. 2008, 22, 2235-2247. [CrossRef]

23. Mishra, V.; Cherkauer, K.A. Retrospective droughts in the crop growing season: Implications to corn and soybean yield in the Midwestern United States. Agricu. For. Meteorol. 2010, 150, 1030-1045. [CrossRef]

24. Shahid, S.; Nath, S.K.; Maksud Kamal, A.S.M. GIS integration of remote sensing and topographic data using fuzzy logic for ground water assessment in Midnapur district, India. Geocarto Int. 2002, 17, 69-74. [CrossRef]

25. Al-Abadi, A.M.; Shahid, S. A comparison between index of entropy and catastrophe theory methods for mapping groundwater potential in an arid region. Environ. Monit. Assess. 2015, 187, 1-21. [CrossRef] [PubMed]

26. Al-Abadi, A.M.; Shahid, S.; Al-Ali, A.K. A GIS-based integration of catastrophe theory and analytical hierarchy process for mapping flood susceptibility: a case study of Teeb area, Southern Iraq. Environ. Earth Sci. 2016, 75, 687. [CrossRef]

27. Ahmed, K.; Shahid, S.; Harun, S.b.; Ismail, T.; Nawaz, N.; Shamsudin, S. Assessment of groundwater potential zones in an arid region based on catastrophe theory. Earth Sci. Inform. 2015, 8, 539-549. [CrossRef]

28. Wang, X.-j.; Zhang, J.-y.; Tong, X.-w.; Shahid, S.; He, R.-m.; Xia, X.-h. Mechanism and comprehensive countermeasure for drought management from the view of catastrophe theory. Nat. Hazards. 2014, 71, 823-835. [CrossRef]

29. Wang, X.-J.; Zhang, J.-Y.; Shahid, S.; Shou-Hai, B.; Rui-Min, H.; Xu, Z. Assessing water security and adaptation measures in a changing environment. Proc. Int. Assoc. Hydrol. Sci. 2015, 366, 129-130.

30. Wang, X.-J.; Zhang, J.-Y.; Shahid, S.; Xia, X.-H.; He, R.-M.; Man-ting, S. Catastrophe theory to assess water security and adaptation strategy in the context of environmental change. Mitig. Adapt. Strat. Gl. 2014, 19, 463-477.

31. Wang, W.; Liu, S.; Zhang, S.; Chen, J. Assessment of a model of pollution disaster in near-shore coastal waters based on catastrophe theory. Ecol. Modell. 2011, 222, 307-312. [CrossRef]

32. Liang, L.; Weng, F.; Yang, G.; Ding, Y. Research on water quality assessment based on catastrophe theory. In Proceedings of the 2nd International Conference on Remote Sensing, Environment and Transportation Engineering, Nanjing, China, 1-3 June 2012.

33. Li, S.F. Assessment of flood hazard risk based on catastrophe theory in flood detention basins. In Proceedings of the International Conference on Electric Technology and Civil Engineering (ICETCE), Lushan, China, 22-24 April 2011.

34. Shahid, S. Rainfall variability and changes in Bangladesh during the last fifty years. In Rainfall: Behavior, Forecasting and Distribution, 1st ed.; Olga, E.M., Tricia, M.R., Eds.; Nova Science Publishers Inc: New York, NY, USA, 2012; pp. 23-44.

35. Shahid, S.; Wang, X.J.; Harun, S.B.; Shamsudin, S.B.; Ismail, T.; Minhans, A. Climate variability and changes in the major cities of Bangladesh: observations, possible impacts and adaptation. Reg. Environ. Change. 2016, 16, 459-471. [CrossRef]

36. Pour, S.H.; Shahid, S.; Chung, E.-S.; Wang, X.-J. Model output statistics downscaling using support vector machine for the projection of spatial and temporal changes in rainfall of Bangladesh. Atmospheric Res. 2018, 213, 149-162. [CrossRef]

37. Shahid, S.; Chen, X.; Hazarika, M.K. Assessment aridity of Bangladesh using geographic information system. Gis Dev. 2005, 9, 40-43.

38. Hossain, M.S.; Qian, L.; Arshad, M.; Shahid, S.; Fahad, S.; Akhter, J. Climate change and crop farming in Bangladesh: An analysis of economic impacts. Int. J. Clim. Chang. Str. 2018, 18. [CrossRef]

39. Rahman, A.Z. Correlations between green revolution and population growth: revisited in the context of Bangladesh and India. Asian Aff. 2004, 26, 41-60. 
40. Yearbook of Agricultural Statistics of Bangladesh. Bangladesh Bureau of Statistics. Ministry of Planning, Bangladesh, 2011. Available online: http:/ / 203.112.218.65:8008/PageWebMenuContent.aspx?MenuKey=234 (accessed on 21 March 2018).

41. Lavell, A.; Oppenheimer, M.; Diop, C.; Hess, J.; Lempert, R.; Li, J.; Muir-Wood, R.; Myeong, S. Climate change: new dimensions in disaster risk, exposure, vulnerability, and resilience. In Managing the Risks of Extreme Events and Disasters to Advance Climate Change Adaptation; Field, C.B., Barros, V., Stocker, T.F., Qin, D., Dokken, D.J., Ebi, K.L., Mastrandrea, M.D., Mach, K.J., Plattner, G.K., Allen, S.K., et al., Eds.; Cambridge University Press: Cambridge, UK; New York, NY, USA; pp. 25-64.

42. Zhang, J.; Zhang, S.; Cheng, M. Effect of Drought on Agronomic Traits of Rice and Wheat: A Meta-Analysis. Int. J. Environ. Res. Public Health. 2018, 15, 839. [CrossRef]

43. Benham, C.J.; Kozak, J.J. Denaturation: an example of a catastrophe II. Two-state transitions. J. Theor. Boil. 1976, 63, 125-149. [CrossRef]

44. Overlay methods. Institute of water research, Michigan State University. 1996. Available online: http:/ / www.iwr.msu.edu/edmodule/gis/foverpn.html. (accessed on 25 January 2009).

45. Nashwan, M.; Shahid, S.; Chung, E.S.; Ahmed, K.; Song, K. Development of Climate-Based Index for Hydrologic Hazard Susceptibility. Sustainability 2018, 10, 2182. [CrossRef]

46. Jenks, G.F. The data model concept in statistical mapping. Int. Yearbook Cartogr. 1967, 7, 186-190.

(C) 2019 by the authors. Licensee MDPI, Basel, Switzerland. This article is an open access article distributed under the terms and conditions of the Creative Commons Attribution (CC BY) license (http://creativecommons.org/licenses/by/4.0/). 